\title{
PERBEDAAN DAYA TAHAN JANTUNG PARU DAN KOMPOSISI TUBUH; PERSENTASE LEMAK TUBUH ANTARA LANJUT USIA ANGGOTA SENAM TAI CHI, WAI TAN KUNG DAN SEDENTER
}

\author{
Novi Vicahyani Utami ${ }^{1,2}$, Leonardo Lubis ${ }^{3}$, Agustina $^{3}$ \\ ${ }^{1}$ Magister Ilmu Kedokteran Dasar, Fakultas Kedokteran, Universitas Padjadjaran \\ ${ }^{2}$ Departemen Farmakologi dan Terapi, Fakultas Kedokteran, Universitas Padjadjaran \\ ${ }^{3}$ Departemen Anatomi, Fisiologi, dan Biologi Sel, Fakultas Kedokteran, Universitas Padjadjaran
}

\begin{abstract}
The benefits of Tai Chi and Wai Tan Kung exercises on cardiopulmonary endurance and body composition have become a controversial issue. The survey analytical comparasional study was performed to investigate the differences of cardiopulmonary endurance and body composition among elderly members of Tai Chi, Wai Tan Kung and elderly sedenter. The study involved 10 elderly members of Tai Chi, 10 elderly members of Wai Tan Kung, and 10 elderly sedenter. The Astrand-Rhyming's step test was conducted to measure the cardiopulmonary endurance. While the measurement of body composition (body fat percentage) was done using skinfold caliper. The data were analyzed with unpaired t-test $(p<0.05)$. The results of the study indicated that cardiopulmonary endurance ( $\mathrm{VO}_{2}$ max) and body composition (body fat percentage) of Tai Chi elderly members were the best of both Wai Tan Kung elderly members and of elderly sedenter; while cardiopulmonary endurance and body composition of Wai Tan Kung elderly members were better than those of elderly sedenter.
\end{abstract}

Keywords:cardiopulmonary endurance, body composition, Tai Chi, Wai Tan Kung, elderly

Korespondensi: Novi Vicahyani Utami, E-mail: utamivicahyaninovi@gmail.com , Departemen Anatomi, Fisiologi, dan Biologi Sel, Fakultas Kedokteran Universitas Padjadjaran. Jalan Raya Jatinangor Km 21, Sumedang, Jawa Barat, Indonesia. 


\section{PENDAHULUAN}

Menurut data Departemen Kesehatan Republik Indonesia (2002), pembangunan di bidang kesehatan telah membantu tercapainya peningkatan usia harapan hidup yaitu 65 tahun (1995-2000) menjadi 67,68 tahun (2000-2005). Kondisi tersebut menggambarkan kemungkinan akan terjadinya peningkatan jumlah lanjut usia (lansia) yang terus menerus dari tahun ke tahun. Oleh karena itu, perlu diberikan perhatian khusus kepada para lansia, agar masyarakat lansia tersebut dapat mempertahankan kebugaran jasmaninya (Depkes, 2002). Adapun yang dimaksud dengan lansia, menurut Undang-Undang No. 13 Tahun 1998 tentang Kesejahteraan Lanjut Usia, adalah seseorang yang telah mencapai usia 60 tahun ke atas (Dinkes Jabar, 2000).

Menurut WHO (2007), 60-85\% lansia di dunia masih bergaya hidup sedenter, yaitu sebagian besar waktunya hanya digunakan untuk duduk-duduk, nonton dan istirahat. Gaya hidup sedenter merupakan gaya hidup yang sangat berbahaya bagi kesehatan karena dapat meningkatkan kemungkinan timbulnya berbagai penyakit, antara lain berbagai penyakit yang terkait dengan perubahan daya tahan jantung paru dan persentase lemak tubuh. Berdasarkan data WHO (2007), 2 juta kematian ternyata berkaitan erat dengan tingkat aktivitas fisik yang rendah (physical inactivity). Sebagian lansia di dunia mulai menyadari hal ini dan berusaha untuk lebih banyak mengisi waktunya dengan berbagai aktivitas fisik, antara lain dengan berolahraga untuk mempertahankan daya tahan jantung paru dan memperbaiki komposisi tubuh. Beberapa olahraga yang cukup populer di kalangan para lansia antara lain senam Tai Chi, senam Wai Tan Kung, senam Lansia dan senam Jantung Sehat. Senam lansia dan senam jantung sehat sudah tidak asing lagi bagi lansia Indonesia, penelitiannya pun sudah banyak dilakukan di Indonesia. Adapun penelitian yang terkait dengan senam Tai Chi dan senam Wai Tan Kung masih terbatas.

Tai Chi maupun Wai Tan Kung merupakan latihan fisik yang berasal dari Tiongkok dan sudah dipraktekkan oleh berjuta-juta orang selama berabad-abad (Tung, 1985; Fuxing, 2001). Kedua bentuk latihan ini termasuk ke dalam jenis latihan aerobik low-impact low-velocity sehingga merupakan bentuk latihan yang cocok bagi para lansia (Lu dan Kuo, 2003). Pada pelaksanaannya di lapangan, latihan Tai Chi dilakukan setiap hari dengan lama latihan 1-1.5 jam, sedangkan Wai Tan Kung dilakukan 6 kali dalam seminggu dengan lama latihan 30-60 menit. Tai Chi termasuk olahraga dengan intensitas sedang, sedangkan Wai Tan Kung termasuk olahraga dengan intensitas ringan ( $\mathrm{Li} \mathrm{dkk}$, 2001; Lu dan Kuo, 2003). Menurut Foss dan
Keteyian (1998), latihan aerobik yang memiliki intensitas lebih tinggi akan memberikan efek latihan yang lebih besar terhadap peningkatan daya tahan jantung paru. Daya tahan jantung paru itu sendiri merupakan salah satu komponen dari kebugaran jasmani yang penilaiannya secara umum dapat dilakukan dengan pengukuran kapasitas aerobik ( $\mathrm{VO}_{2}$ maks) (McArdle dkk, 2001).

Selain daya tahan jantung paru, komponen kebugaran jasmani lain yang penting diperhatikan pada lansia ialah komposisi tubuh (persentase lemak tubuh). Pertambahan usia biasanya disertai dengan perubahan komposisi tubuh, penurunan fungsi organ dan metabolisme (Weinsier, 2002). Pada kelompok lansia umumnya terdapat kecenderungan penurunan aktivitas fisik sehingga terjadi ketidakseimbangan antara asupan kalori harian dengan penggunaan kalori harian yang kemudian mengakibatkan perubahan persentase lemak tubuh (Wilmore, 2004; Weinsier, 2002). Persentase lemak tubuh yang meningkat dapat menimbulkan berbagai masalah kesehatan (McArdle dkk, 2001).

Penelitian Lan, dkk. (1996) dan Lan, dkk. (1998) di Taiwan menyebutkan bahwa Tai Chi dapat bermanfaat bagi daya tahan jantung paru, namun penelitian lain yang dilakukan oleh Young, dkk. (1998) menyebutkan bahwa latihan Tai Chi tidak memberikan manfaat terhadap daya tahan jantung paru. Tentang penelitian mengenai Wai Tan Kung masih sangat terbatas. Penelitian yang terkait dengan komposisi tubuh lansia yang berlatih Tai Chi maupun Wai Tan Kung pun masih terbatas. Selain itu, keuntungan latihan Tai Chi dan Wai Tan Kung terhadap daya tahan jantung paru dan komposisi tubuh merupakan hal yang masihkontroversial. Keterbatasan informasi ilmiah dan perbedaan pendapat para ahli inilah yang menyebabkan penulis tertarik untuk meneliti mengenai kondisi daya tahan jantung paru dan komposisi tubuh lansia anggota senam Tai Chi dan Wai Tan Kung, dan dibandingkan dengan lansia sedenter. Penilaian daya tahan jantung paru dilakukan dengan pengukuran $\mathbf{V O}_{2}$ maks (dengan tes bangku AstrandRhyming), sedangkan penilaian komposisi tubuh dilakukan dengan pengukuran persentase lemak tubuh.

Penelitian ini dapat menjadi informasi kepada kelompok lansia, sebagai salah satu upaya menciptakan kehidupan yang sehat dan berkualitas bagi para lansia. 


\section{METODE}

Pengambilan subjek penelitian dilakukan secara total sampling, didapatkan jumlah subjek 10 orang dari kelompok Tai Chi, 10 orang dari kelompok Wai Tan Kung dan 10 orang dari kelompok sedenter. Penelitian ini merupakan penelitian survei analitik komparasional.

Parameter daya tahan jantung paru pada penelitian ini ialah kapasitas aerobik $\left(\mathrm{VO}_{2}\right.$ maks $)$, diukur dengan tes bangku Astrand-Rhyming. Komposisi tubuh pada penelitian ini mengacu pada persentase lemak tubuh. Pada penelitian ini persentase lemak tubuh didapatkan berdasarkan hasil pengukuran tebal lipatan kulit pada 4 tempat, yaitu biceps, triceps, subscapula, dan suprailiaca dengan menggunakan skinfold caliper.Persentase lemak tubuh sangat dipengaruhi oleh asupan kalori dan penggunaan kalori harian, sehingga pada penelitian ini juga dihitung jumlah asupan kalori dan total penggunaan kalori (total energy expenditure). Penilaian asupan kalori harian menggunakan metode recall 3 x 24 jam yang dilakukan dengan wawancara dan pengisian kuesioner. Total penggunaan kalori dihitung berdasarkan perhitungan energi untuk metabolisme basal, melakukan aktivitas fisik (dengan record aktivitas fisik 7 hari berturut-turut), dan kegiatan dinamik khusus makanan (specific dynamic action). Data hasil penelitian dianalisis dengan uji-t tidak berpasangan $(\mathrm{p} \leq 0,05)$.

HASIL DAN PEMBAHASAN

Tabel 1 Karakteristik Fisik Fisiologis Lansia Anggota Senam Tai Chi, Wai Tan Kung dan Lansia Sedenter

Variabel

Tai Chi

\section{Rata-rata dan Simpangan Baku}

Wai Tan Kung

\begin{tabular}{|c|c|c|c|c|c|c|c|c|c|}
\hline 1. Umur (tahun) & 66,30 & \pm & 4,60 & 66,40 & \pm & 3,70 & 66,30 & \pm & 2,80 \\
\hline 2. Berat ( kg ) & 55,85 & \pm & 9,50 & 56,80 & \pm & 6,50 & 55,20 & \pm & 13,60 \\
\hline 3. Tinggi ( $\mathrm{m}$ ) & 1,52 & \pm & 0,06 & 1,49 & \pm & 0,04 & 1,46 & \pm & 0,10 \\
\hline 4. IMT $\left(\mathrm{kg} / \mathrm{m}^{2}\right)$ & 24,15 & \pm & 4,10 & 25,64 & \pm & 2,70 & 25,75 & \pm & 4,80 \\
\hline 5. $\overline{\mathrm{V}} \mathrm{O}_{2}$ maks $(\mathrm{ml} / \mathrm{kgBB} / \mathrm{mnt})$ & 30,18 & \pm & 2,44 & 27,94 & \pm & 2,68 & 25,94 & \pm & 0,82 \\
\hline 6. Lemak Tubuh (\%) & 21,29 & \pm & 4,30 & 25,03 & \pm & 3,87 & 29,27 & \pm & 6,23 \\
\hline 7. Asupan Kalori (kilokalori) & 2711.83 & \pm & 460.93 & 2503.98 & \pm & 303,07 & 2359.80 & \pm & 579.36 \\
\hline 8. TEE (kilokalori) & 2157,06 & \pm & 186,69 & 2034,63 & \pm & 120,08 & 1935,84 & \pm & 246,26 \\
\hline
\end{tabular}

Tabel 2 Hasil Uji-t Tidak Berpasangan Daya Tahan Jantung Paru dan Komposisi Tubuh Lansia Anggota Senam Tai Chi, Wai Tan Kung, dan Lansia Sedenter

\begin{tabular}{|c|c|c|c|c|c|}
\hline Variabel & $\begin{array}{c}\text { Kelompok } \\
\text { Sampel }\end{array}$ & $\begin{array}{c}\text { Rata-rata } \pm \\
\text { SD }\end{array}$ & t-hitung & t-tabel & Keterangan \\
\hline \multirow{6}{*}{$\overline{\mathrm{V}}_{2}$ maks } & Tai Chi & $30,18 \pm 2,44$ & & & \multirow{2}{*}{$\begin{array}{c}\text { sangat } \\
\text { bermakna }\end{array}$} \\
\hline & Sedenter & $25,94 \pm 0,82$ & $5,204 * *$ & 2,896 & \\
\hline & Wai Tan Kung & $27,94 \pm 2,68$ & & & \multirow[b]{2}{*}{ bermakna } \\
\hline & Sedenter & $25,94 \pm 0,82$ & $2,250 *$ & 1,833 & \\
\hline & Tai Chi & $30,18 \pm 2,44$ & & & \\
\hline & Wai Tan Kung & $27,94 \pm 2,68$ & $1,953^{*}$ & 1,734 & bermakna \\
\hline \multirow{6}{*}{ \% Lemak } & Tai Chi & $21,29 \pm 4,30$ & & & \multirow{2}{*}{$\begin{array}{c}\text { sangat } \\
\text { bermakna }\end{array}$} \\
\hline & Sedenter & $29,27 \pm 6,23$ & $-3,332 * *$ & $-2,552$ & \\
\hline & Wai Tan Kung & $25,03 \pm 3,87$ & & & \multirow[b]{2}{*}{ bermakna } \\
\hline & Sedenter & $29,27 \pm 6,23$ & $-1,828^{*}$ & $-1,823$ & \\
\hline & Tai Chi & $21,29 \pm 4,31$ & & & \multirow[b]{2}{*}{ bermakna } \\
\hline & Wai Tan Kung & $25,03 \pm 3,87$ & $-2,044 *$ & $-1,734$ & \\
\hline
\end{tabular}

Keterangan: $\mathrm{p}<0,05$ 
Perbedaan Daya Tahan Jantung Paru ( $\mathrm{VO}_{2}$ maks) Antara Lansia Anggota Senam Tai Chi, Wai Tan Kung dan Lansia Sedenter

Hasil penelitian menunjukan bahwa daya tahan jantung paru $\left(\mathrm{VO}_{2}\right.$ maks)lansia anggota senam Tai Chi lebih besar daripada lansia sedenter $(30,18 \pm$ 2,44 vs $25.94 \pm 0.82 \mathrm{ml} / \mathrm{kgBB}^{\prime}$ menit), begitupula daya tahan jantung paru $\left(\mathrm{VO}_{2}\right.$ maks)lansia anggota senam Wai Tan Kung lebih besar daripada lansia sedenter $(27.94 \pm 2.68$ vs $25.94 \pm 0.82 \mathrm{ml} / \mathrm{kgBB} /$ menit), dan daya tahan jantung paru $\left(\mathrm{VO}_{2}\right.$ maks)lansia anggota senam Tai Chi lebih besar daripada lansia anggota senam Wai Tan Kung (30.18 2.44 vs $27.94 \pm 2.68$ $\mathrm{ml} / \mathrm{kgBB}$ 'menit). Hasil tersebut tercantum pada tabel 3.1 dan 3.2. Terdapat perbedaan kategori kebugaran jasmani berdasarkan daya tahan jantung paru $\left(\mathrm{VO}_{2}\right.$ maks)pada ketiga kelompok lansia tersebut. Nilai rata-rata daya tahan jantung paru $\left(\mathrm{VO}_{2}\right.$ maks)lansia anggota senam Tai Chi $\quad(30.18 \pm 2.44$ $\mathrm{ml} / \mathrm{kgBB}$ 'menit) termasuk kategori cukup, sedangkan rata-rata daya tahan jantung paru $\left(\mathrm{VO}_{2}\right.$ maks)lansia anggota senam Wai Tan Kung $(27.94 \pm 2.68 \mathrm{ml} / \mathrm{kgBB}$ 'menit) termasuk kategori kurang, demikian pula rata-rata daya tahan jantung paru $\left(\mathrm{VO}_{2}\right.$ maks)lansia sedenter $\quad(25.94 \pm 0.82$ $\mathrm{ml} / \mathrm{kgBB}$ 'menit) termasuk kategori kurang.

Hasil penelitian menunjukan bahwa daya tahan jantung paru lansia anggota senam Tai Chi lebih baik daripada lansia sedenter. Hal ini dapat dijelaskan karena lansia anggota senam Tai Chi melakukan latihan Tai Chi setiap hari dengan intensitas latihan yang sedang dan lama latihan antara1-1.5jam, sedangkan lansia sedenter relatif sedikit melakukan aktivitas fisik dan banyak menghabiskan waktunya untuk duduk-duduk, nonton, dan istirahat. Latihan Tai Chi termasuk jenis latihan aerobik. Latihan aerobik yang dilakukan secara teratur dapat meningkatkan daya tahan jantung paru. Daya tahan jantung paru sangat dipengaruhi oleh kapasitas paru, kemampuan hemoglobin untuk mengikat $\mathrm{O}_{2}$, kemampuan pompa jantung, dan perfusi $\mathrm{O}_{2}$ dari pembuluh darah perifer ke dalam otot. Melakukan latihan Tai Chi yang termasuk latihan aerobik tersebut, maka daya tahan jantung paru menjadi lebih baik karena terjadi peningkatan kapasitas paru akibat gerakan Tai Chi yang lembut, terus menerus, disertai dengan penarikan dan penghembusan nafas panjang. Hal ini akan meningkatkan kemampuan otot-otot pernafasan, meningkatkan elastisitas rongga dada dan paru-paru, sehingga kemampuan pengembangan paru-paru dan dinding dada meningkat pula. Proses difusi $\mathrm{O}_{2}$ ke pembuluh kapiler paru pun meningkat. Hal ini didukung oleh hasil penelitian yang dilakukan oleh Brown dkk. (1989) yang menunjukkan bahwa laki-laki yang melakukan latihan Tai Chi memiliki minute ventilation, stroke volume dan cardiac output yang lebih besar dibandingkan kelompok kontrol. Hal ini menunjukkan pula bahwa latihan Tai Chi tidak hanya meningkatkan kapasitas paru, namun juga meningkatkan fungsi jantung. Latihan Tai Chi yang termasuk jenis latihan aerobik akan meningkatkan efisiensi kerja jantung melalui dua mekanisme, yaitu jumlah darah yang dipompa setiap kali denyut lebih besar dan frekuensi denyutan berkurang. Selain itu, latihan aerobik juga meningkatkan kadar enzim yang berpengaruh pada peningkatan pengikatan $\mathrm{O}_{2}$ oleh $\mathrm{Hb}$ (Henderson, 2000). Selain itu pula, latihan Tai Chi yang merupakan latihan aerobik meningkatkan kemampuan otot untuk mengkonsumsi oksigen secara maksimal. Hal ini terjadi karena luas permukaan difusi $\mathrm{O}_{2}$ di dalam otot meningkat sehingga difusi $\mathrm{O}_{2}$ dari kapiler ke otot menjadi lebih mudah, difusi $\mathrm{CO}_{2}$ dari otot ke kapiler menjadi lebih mudah dan metabolisme aerobik pembentukan energi dalam otot menjadi lebih baik (Miller, 2005).

Dari uraian yang penulis paparkan dapat dijelaskan bahwa latihan Tai Chi dapat meningkatkan daya tahan jantung paru. Hal inilah yang memperjelas mengapa lansia anggota senam Tai Chi dapat memiliki nilai rata-rata $\mathrm{VO}_{2}$ makssebesar $30.18 \pm 2.44 \mathrm{ml} / \mathrm{kgBB} /$ menit, sedangkan lansia sedenter memiliki nilai rata-rata $\quad \mathrm{VO}_{2}$ maksyang lebih kecil, yaitu 25.94 \pm 0.82 $\mathrm{ml} / \mathrm{kgBB} /$ menit.

Sesuai dengan uraian sebelumnya, senam Wai Tan Kung pun dapat meningkatkan daya tahan jantung paru. Senam Wai Tan Kung dilakukan dengan frekuensi 6 kali per minggu, intensitas ringan dan lama latihan sekitar 30-60 menit. Gerakan pada senam Wai Tan Kung pun termasuk gerakan yang ritmis, relaks, berkesinambungan dan disertai penarikan serta penghembusan nafas secara tenang dan dalam. Seperti halnya pada Tai Chi, latihan Wai Tan Kung yang termasuk jenis latihan aerobik, juga dapat meningkatkan daya tahan jantung paru melalui peningkatan kapasitas paru, kemampuan hemoglobin untuk mengikat $\mathrm{O}_{2}$, kemampuan pompa jantung, dan perfusi $\mathrm{O}_{2}$ dari pembuluh darah perifer ke dalam otot. Uraian penulis sebelumnya yang memaparkan mengapa Tai Chi dapat meningkatkan daya tahan jantung paru juga dapat menjelaskan mengapa lansia anggota senam Wai Tan Kung memiliki nilai rata-rata $\mathrm{VO}_{2}$ maksyang lebih besar daripada lansia sedenter (27.94 \pm 2.68 vs $25.94 \pm 0.82 \mathrm{ml} / \mathrm{kgBB} /$ menit).

Hasil penelitian menunjukkan bahwa daya tahan jantung paru $\left(\mathrm{VO}_{2}\right.$ maks) lansia anggota senam Tai Chi lebih besar daripada lansia anggota senam Wai Tan Kung (30.18 \pm 2.44 vs $27.94 \pm 2.68$ $\mathrm{ml} / \mathrm{kgBB} / \mathrm{menit}$ ). Hal ini terjadi karena senam Tai 
Chi dan senam Wai Tan Kung yang dilakukan memiliki frekuensi, intensitas, dan lama latihan yang berbeda, meskipun keduanya sama-sama termasuk jenis latihan aerobik. Tai Chi termasuk latihan intensitas sedang, sedangkan Wai Tan Kung termasuk latihan intensitas ringan. Durasi latihan Tai Chi lebih lama dibandingkan Wai Tan Kung (1.-1.5 jam vs 30-60 menit). Perbedaan ini akan memberikan efek latihan yang berbeda pula. Hal ini sesuai dengan pernyataan Wood dkk. (1995) bahwa latihan aerobik dengan intensitas yang lebih rendah akan dapat mengimbangi efek latihan aerobik dengan intensitas yang lebih tinggi jika dilakukan dalam durasi yang lebih lama. Tai Chi dilakukan dengan intensitas yang lebih tinggi dan durasi yang lebih lama dibandingkan Wai Tan Kung. Uraian di atas dapat menjelaskan mengapa lansia anggota senam Tai Chi dapat memiliki nilai rata-rata $\mathrm{VO}_{2}$ maks yang lebih besar dibandingkan lansia anggota senam Wai Tan Kung.

Perbedaan Komposisi Tubuh (\% Lemak) Antara Lansia Anggota Senam Tai Chi, Wai Tan Kung dan Lansia Sedenter

Hasil penelitian menunjukkan bahwa komposisi tubuh (\%lemak) lansia anggota senam Tai Chi lebih baik daripada lansia sedenter $(21.29 \pm 4.30$ vs $29.27 \pm 6.23 \%$ ), begitupula komposisi tubuh (\%lemak) lansia anggota senam Wai Tan Kung lebih baik daripada lansia sedenter $(25.03 \pm 3.87$ vs $29.27 \pm 6.23 \%$ ), dan komposisi tubuh (\%lemak) lansia anggota senam Tai Chi lebih baik daripada lansia anggota senam Wai Tan Kung $(21.29 \pm 4.30$ vs $25.03 \pm 3.87 \%$ ). Hal ini berarti terdapat perbedaan kategori persentase lemak tubuh pada ketiga kelompok tersebut. Nilai rata-rata persentase lemak tubuh lansia anggota senam Tai Chi $(21.29 \pm 4.30 \%)$ termasuk kategori cukup, sedangkan rata-rata persentase lemak lansia anggota senam Wai Tan Kung $(25.03 \pm 3.87 \%)$ termasuk kategori lebih, demikian pula rata-rata persentase lemak lansia sedenter $(29.27 \pm 6.23 \%)$ termasuk kategori lebih.

Hasil penelitian yang menunjukkan bahwa komposisi tubuh (\%lemak) lansia anggota senam Tai Chi lebih baik daripada lansia sedenter dapat dijelaskan bahwa dengan tingkat pengeluaran energi yang lebih banyak pada kelompok Tai Chi dibandingkan kelompok sedenter $(2157.06 \pm 186.89$ vs $1935.84 \pm 246.26 \mathrm{kkal})$. Nilai total penggunaan kalori tersebut merupakan gabungan jumlah energi yang dibutuhkan untuk metabolisme basal, specific dynamic action, dan aktivitas fisik termasuk latihan Tai Chi yang dilakukan subjek. Penelitian Zhuo, dkk. (1984) menunjukkan bahwa latihan Tai Chi termasuk latihan intensitas sedang dengan tingkat pengeluaran energi sebesar 4.1 METs. Pada penelitian ini, lansia anggota senam Tai Chi melakukan latihan selama 1-1.5 jam dan memiliki nilai rata-rata berat badan $55.85 \pm 9.50 \mathrm{~kg}$ yang berarti jumlah kalori yang digunakan oleh para lansia tersebut untuk satu kali berlatih Tai Chi selama 1-1.5 jam berkisar antara 228.98 kkal hingga 343.48 kkal. Dapat diperhatikan pada tabel 3.1 bahwa selisih rata-rata TEE antara kelompok Tai Chi dan sedenter ialah 221.22 kkal. Hal ini menunjukkan bahwa energi total yang digunakan untuk aktivitas fisik harian lainnya pada kelompok Tai Chi hampir sama dengan kelompok sedenter, sehingga tampak bahwa latihan Tai Chi merupakan aktivitas yang memang membantu peningkatan jumlah total penggunaan energi pada kelompok Tai Chi. Meskipun demikian, terdapat keanehan jika diperhatikan bahwa asupan kalori kelompok Tai Chi lebih tinggi dibandingkan asupan kalori kelompok sedenter, padahal komposisi tubuh (\%lemak) kelompok Tai Chi lebih baik daripada sedenter. Hal ini dapat dijelaskan dengan hasil penelitian Johnson dkk. (1994) yang menyimpulkan bahwa seringkali terjadi underreporting dari wawancara asupan kalori pada subjek yang gemuk atau overweight. Berdasarkan klasifikasi Depkes (1994), subjek kelompok sedenter termasuk kategori overweight. Selain itu, keganjilan ini dapat pula dijelaskan dengan adanya teori yang mengatakan bahwa latihan fisik dapat meningkatkan basal metabolic rate (Wilmore, 1994). Dengan BMR yang meningkat, berarti pengeluaran energi dapat lebih tinggi dari nilai estimasi.

Untuk menjelaskan hasil penelitian yang menunjukkan bahwa komposisi tubuh (\% lemak) lansia anggota senam Tai Chi lebih baik daripada sedenter, perlu juga diperhatikan bahwa latihan Tai Chi termasuk latihan aerobik intensitas sedang. Penelitian Bouchard, dkk. (1993) menunjukkan bahwa latihan aerobik dengan intensitas sedang yang dilakukan secara teratur dapat menurunkan persentase lemak tubuh. Latihan aerobik intensitas sedang ini berpengaruh terhadap peningkatan oksidasi lemak baik pada saat latihan ataupun saat istirahat, meskipun menurut Bouchard dkk. (1995) besarnya pengaruh terhadap peningkatan oksidasi lemak ini berbeda-beda antar individu. Pada latihan aerobik intensitas ringan dan sedang, sumber energi utama yang digunakan berasal dari lemak. Seperti diungkapkan oleh Powers (1997) bahwa latihan dengan intensitas ringan dan sedang tidak menstimulasi proses glikolisis, namun yang terjadi adalah peningkatan oksidasi asam lemak sebagai sumber energi. Otot menggunakan energi dari asam lemak bebas dan trigliserida. Semakin lama kontraksi otot semakin meningkat lipolisis (Schrauwen, 2002). Selain intensitas latihan, durasi 
latihan juga perlu diperhatikan untuk menurunkan persentase lemak tubuh. Menurut Powers (1997), untuk menurunkan lemak tubuh diperlukan waktu lebih dari 30 menit setiap kali latihan karena dalam waktu tersebut mulai terjadi lipolisis di jaringan adiposa. Proses lipolisis juga dipengaruhi oleh adrenalin yang akan merangsang lipase (Guyton, 2005). Kadar adrenalin akan mencapai puncak pada menit ke 60 dari rangkaian latihan fisik yang dilakukan, sehingga latihan yang dilakukan selama satu jam atau lebih akan memiliki efek yang cukup baik bagi penurunan persentase lemak tubuh. Latihan Tai Chi pada penelitian ini dilakukan dengan durasi 1-1.5 jam, sehingga latihan Tai Chi yang dilakukan secara teratur dapat menurunkan persentase lemak tubuh.

Begitu pula halnya dengan latihan Wai Tan Kung secara teratur yang dilakukan selama 30-60 menit dengan intensitas ringan dapat menurunkan persentase lemak tubuh. Pada penelitian ini, komposisi tubuh (\%lemak) lansia anggota senam Wai Tan Kung lebih baik daripada komposisi tubuh (\%lemak) lansia sedenter ( $25.03 \pm 3.87$ vs $29.27 \pm 6.23$ $\%)$. Selain penjelasan mengenai durasi latihan yang sudah dibahas sebelumnya, hal ini juga dapat dijelaskan dengan memperhatikan sisi intensitas latihan Wai Tan Kung yang termasuk intensitas ringan. Hal ini sesuai dengan hasil penelitian Schrauwen dkk. (2002) yang menunjukkan bahwa program latihan aerobik intensitas ringan yang dilakukan 2 jam per minggu (durasi latihan $\quad 47 \pm 2.5$ menit, frekuensi 3 kali per minggu) dapat meningkatkan oksidasi lemak. Dari uraian tersebut, dapat dijelaskan bahwa lansia anggota senam Tai Chi maupun Wai Tan Kung memiliki komposisi tubuh (\%lemak) yang lebih baik dari lansia sedenter.

Adapun hasil penelitian yang menunjukkan bahwa komposisi tubuh (\%lemak) lansia anggota senam Tai Chi lebih baik daripada komposisi tubuh (\%lemak) lansia anggota senam Wai Tan Kung $(21.29 \pm 4.30$ vs $25.03 \pm 3.87 \%)$ dapat dijelaskan dengan memperhatikan perbedaan kedua latihan tersebut dari sisi intensitas dan lama latihan. Menurut Wood dkk. (1995) latihan aerobik dengan intensitas yang lebih rendah akan dapat mengimbangi efek latihan aerobik dengan intensitas yang lebih tinggi jika dilakukan dalam durasi yang lebih lama. Pada penelitian ini, kelompok Tai Chi melakukan latihan dengan intensitas yang lebih tinggi dan durasi yang lebih lama dibandingkan dengan kelompok Wai Tan Kung sehingga lansia anggota senam Tai Chi memiliki komposisi tubuh (\%lemak) yang lebih baik dari lansia anggota senam Wai Tan Kung.

\section{KESIMPULAN}

Berdasarkan hasil penelitian bahwa Tai chi lebih baik dalam meningkatkan daya tahan jantung paru dan membantu menjaga komposisi lemak tubuh.

8. Guyton, A. C.; Hall, J. E. 2005. Textbook of Medical Physiology $11^{\text {th }}$ Edition. Philadelphia: W. B. Saunders Company

9. Henderson, K.K., McCance, W., Urano, T., Kuwahira, I., Clancy, R., and Gonzales, N.C. 2000. Acute vs Chronic Effects of Elevated Hemoglobin $\mathrm{O}_{2}$ Affinity on $\mathrm{O}_{2}$ Transport in Maximal Exercise. $J$ of Appl Physiol 89: 265-272.

10. Johnson, R.K., Goran, M.I., Peohlman, E.T. 1994. Correlates of Over and Underreporting of Energy Intake in Healthy Older Men and Woman. Am J Clin Nutr 59:1286-1290.

11. Lan, C., Lai, J., Wong, M. 1996. Cardiorespiratory Function, Flexibility, And Body Composition Among Geriatric Tai Chi Chuan Practitioners. Taipei: Department of Physical Medicine and Rehabilitation, National Taiwan University Hospital.

12. Lan, C., Lai, J., Wong, M. 1998. 12-Month Tai Chi Training In The Elderly: Its Effect On Health Fitness. Med \& Sci in Sports \& Exercise. 30(3) : 345-351

7. Fuxing, Zhang. 2001. Handbook of Tai Chi Chuan Exercises. Jakarta: Grasindo. 
13. Li, JX; Hong, Y; Chan, KM. 2001. Tai Chi: Physiological Characteristics And Beneficial Effects On Health. British J of Sports Med. 35:148-156.

14. Lu, W.A. \& Kuo, C.D. 2003. The Effect of Wai Tan Kung on Autonomic Nervous Modulation in The Elderly. J Biomed Sci. 10:697-705.

15. McArdle, W.D., Katch, F., Katch, V. 2001. Exercise Physiology: Energy, Nutrition and HumanPerformance. $5^{\text {th }} \mathrm{Ed}$. United States: Williams and Wilkins.

16. Miller, J.M., Pegelow, D.F., Jacques, A.J., Dempsey, J.A. 2005. Skeletal Muscle Pump vs Respiratory Muscle Pump; Modulation of Venous Return From The Locomotor Limb in Humans. $J$ of Physiol. 563:925-943.

17. Powers, S.K., Howley E.T. 2001. Exercise Physiology: Theory and Application to Fitness and Performance. $4^{\text {th }} E d$. New York: Mc Graw Hill Company.

18. Schrauwen, P., Dorien, P.C., Hul, G., Wagenmakers, A.J.M., Vidal, H., Saris, W.H.M., Baak, M.A. 2002. The Effect of a 3-Month Low Intensity Endurance Training Program on Fat Oxidation and Acetyl-CoA Carboxylase-2 Expression. Diabetes J. 51:22202226.
19. Tung, C. 1985. Mengenal Olahraga Senam Wai Tan Kung. Jakarta: Waitankung Indonesia.

20. Weinsier, R., Hunter, G., Desmond, R.A. 2002. Free Living Activity Energy Expenditure in Woman Successful and Unsuccessful at Maintaining a Normal Body Weight. American $J$ of Clin Nutr. 75(3) : 499-504

21. WHO. 2007. Sedentary Lifestyle: A Global Public Health Problem. Melalui $<w w w . w h o . i n t / e n t i t y / m o v e f o r h e a l t h / a d v o c a c y /$ inform ation_sheets/sedentary/en/index.html $\geq$ [09/01/06]

22. Wilmore J.H., Costill, L.D. 2004. Physiology of Sport and Exercise. United States: The United States of America Ltd. Human Kinetics Publisher.

23. Wood, P., Terry, R., Haskell W. 1995. Metabolism of Substrates: Diet, Lipoprotein, Metabolism and Exercise. Fed Proc. 44(2):358-363.

24. Young, D., Appel, L., Jee, S. 1998. The Effects of Aerobic Exercise and T'ai Chi on Blood Pressure in the Elderly. Abstracts of the $38^{\text {th }}$ Annual Conference on Cardiovascular Disease Epidemiology and Prevention.

25. Zhuo, D., Shepard, R.J., Plyley, M.J., Davis, G.M. 1984. Cardiorespiratory and Metabolic Responses During Tai Chi chuan Exercise. Canadian J of Appl Sport Sci .9(1):7-10. 